\title{
Developmental Dysplasia of Hip: Perspectives in Genetic Screening
}

\author{
Radoslav Zamborsky ${ }^{1, *}$, Milan Kokavec ${ }^{1}$, Stefan Harsanyi ${ }^{2}{ }^{\mathbb{D}}$, Doaa Attia ${ }^{3}$ and \\ Lubos Danisovic ${ }^{2}$ (1)
}

1 Department of Orthopaedics, Faculty of Medicine, Comenius University and National Institute of Children's Diseases, Limbova 1, 83340 Bratislava, Slovakia; milan.kokavec@hotmail.com

2 Institute of Medical Biology, Genetics and Clinical Genetics, Faculty of Medicine, Comenius University, Sasinkova 4, 81108 Bratislava, Slovakia; stefan.harsanyi@fmed.uniba.sk (S.H.);

lubos.danisovic@fmed.uniba.sk (L.D.)

3 Department of Internal Medicine, Faculty of Medicine, Alexandria University, Chamblion St., Azarita, 21131 Alexandria, Egypt; doaa.attia@gmail.com

* Correspondence: radozamborsky@gmail.com; Tel.: +421-905-363974

Received: 8 January 2019; Accepted: 10 April 2019; Published: 11 April 2019

\begin{abstract}
Development dysplasia of the hip (DDH) is a complex developmental disorder despite being a relatively common condition mainly caused by incompatibility of the femoral head and the abnormal joint socket. Development dysplasia of the hip describes a wide spectrum of disorders ranging from minor acetabular dysplasia to irreducible dislocation of the hip. Modern medicine still suffers from lack of information about screening and precise genetic examination. Genome wide linkage and association studies have brought significant progress to DDH diagnosis. Association studies managed to identify many candidate (susceptible) genes, such as PAPPA2, COL2A1, HOXD9, GDF-5, and TGFB1, which play a considerable role in the pathogenesis of DDH. Early detection of DDH has a big chance to help in preventing further disability and improve the psychological health and quality of life in those children. This emphasizes the importance to establish a universal screening program along with the genetic counseling.
\end{abstract}

Keywords: developmental dysplasia of hip; DDH screening; genetic factors; associated genes

\section{Introduction}

Developmental dysplasia of the hip (DDH) is a complex musculoskeletal disease, which represents a wide spectrum of pathology, ranging from an asymptomatic form, with only mild radiological deviations, to minor joint instability, acetabular dysplasia, subluxation and to irreducible hip dislocation [1,2]. Development dysplasia of the hip could be an isolated disease or associated with other conditions such as club feet, cardiac anomalies, and renal problems. Untreated DDH can lead to secondary damage to femur, destruction of the joint cartilage and, later on, even to severe movement impairment at any age [3,4].

Persistent DDH might lead to premature osteoarthritis (OA) in adulthood [5]. Kolundžić et al. [6] conducted a prospective cohort study confirming that DDH is a major risk factor to develop severe OA that requires arthroplasty. Similar situations occur in mild forms of DDH that can be missed in newborns, and without treatment, can lead to earlier senior OA, for which the end-stage treatment could be total hip replacement.

Genetic components play crucial roles in the pathogenesis of DDH. Genetic risk exhibited a large familial segregation [1,7]. Studies reported a 30-fold increase for DDH among siblings and children with a previous family history of DDH. This strong genetic basis has been confirmed in a 
twin-concordance study with a higher incidence among monozygotic (41\%) compared to dizygotic twins, and with $5 \%$ recurrence rate for the subsequently born children [8].

\section{Diagnosis and Pathology}

Historic data shows that hip dysplasia has been known since ancient times (Hippocrates) and with technological and theoretical advancement through the centuries, from which ultrasonography was the most helpful, researchers were able to define this disorder and prepare methods to treat it. Notable names from the 20th century such as Marino Ortolani (Ortolani's maneuver, pillow method) or Bedrich Frejka (modificated pillow method) are connected with diagnostic and treatment methods that are still in use [9].

Development dysplasia of the hip can be diagnosed in childhood, but also in adults. Statistically, it affects mainly females with a sex ratio of 5:1. Higher occurrence of DDH in females is in some literature said to be caused by relaxin, a hormone which affects laxity of pelvic ligaments in the mother and has stronger effect on the female fetus, but this theory needs to be further explored. Left hip is more affected in $37 \%$ of patients compared to $26.5 \%$ in bilateral affection [10]. Incidence of DDH varies greatly with countries and continents, but an estimated incidence of 1/34 cases of DDH/1000 live births was reported worldwide. However, the incidence is higher in certain areas such as Middle East, gulf area, and Italy $[1,10]$.

This variation in the different geographical locations is due to the difference in the diagnostic modalities and timing of evaluation [1,11]. This is also the reason of controversy in the literature regarding DDH research data such as prevalence, incidence and diagnosis. Moreover, the high consanguinity rate in the Gulf area attributes to such a high incidence of DDH as well $[1,4,12]$.

The etiology of DDH is multifactorial. It consists of genetic, environmental, and mechanical risk factors. The environmental and mechanical causes include high birth weight (HBW), breech presentation, oligohydramnios, primiparity, intrauterine malposition, swaddling, and laxity of ligaments $[3,10,13]$.

Studies conducted in Asia reported the existence of genes which could be associated with this disorder. Shi et al. [2] reported the possible correlation between the pregnancy-associated plasma protein A2 (PAPPA-2) and DDH among the Chinese Han population. Recently, exome sequencing and genome linkage studies in large families segregating DDH have been useful to identify some variants in the genes involved in chondrogenesis and bone formation that have been reported to be associated with DDH such as collagen alpha-1(I) chain gene (COL1A1) and vitamin D receptor (VDR) [14].

Despite the lack of standardized screening methods to detect DDH in early age, neonatal physical examination and ultrasonography (U/S) play a crucial role to detect early conditions and decrease the risk of complications (Figures 1-3). Approximately $97 \%$ of orthopedic surgeons use U/S to diagnose DDH before the age of three, however, pelvic radiography is a better imaging tool for children after the age of 3 years [15].

The future in treatment is early screening, diagnosis and treatment. Without reliable genetic examination there cannot be an effective approach to early therapy. The goal of treatment is to obtain a safe reduction of the hip conservatively and to avoid surgical intervention and long-term disabilities. In this review, we provide a better understanding of DDH and bridge the gap between genetic causes and molecular mechanisms. 

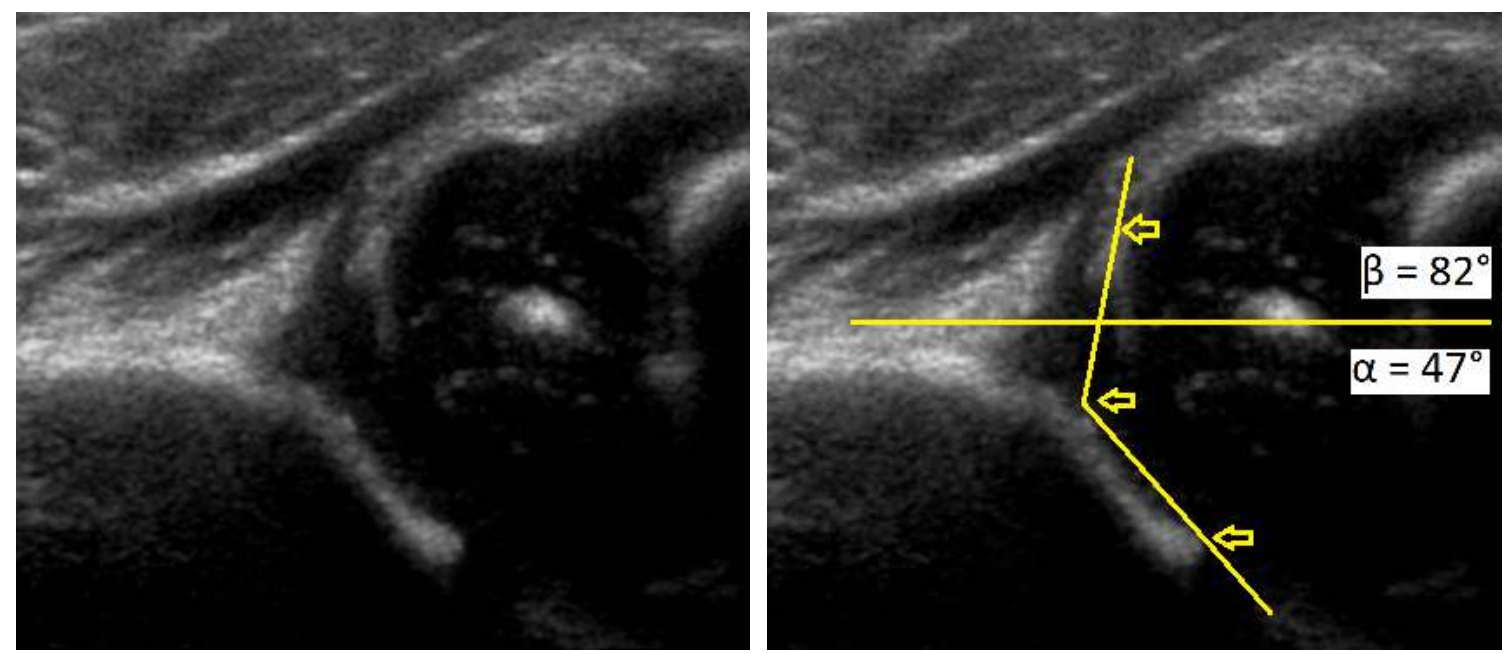

Figure 1. Development dysplasia of the hip (DDH)-ultrasound. In Graf's classification type D (Decentring hip): Bony roof is severely deficient, bony rim is rounded to flattened, cartilage roof is displaced, $\alpha$ angle is $43-49^{\circ}$ and $\beta$ angle $>77^{\circ}$.
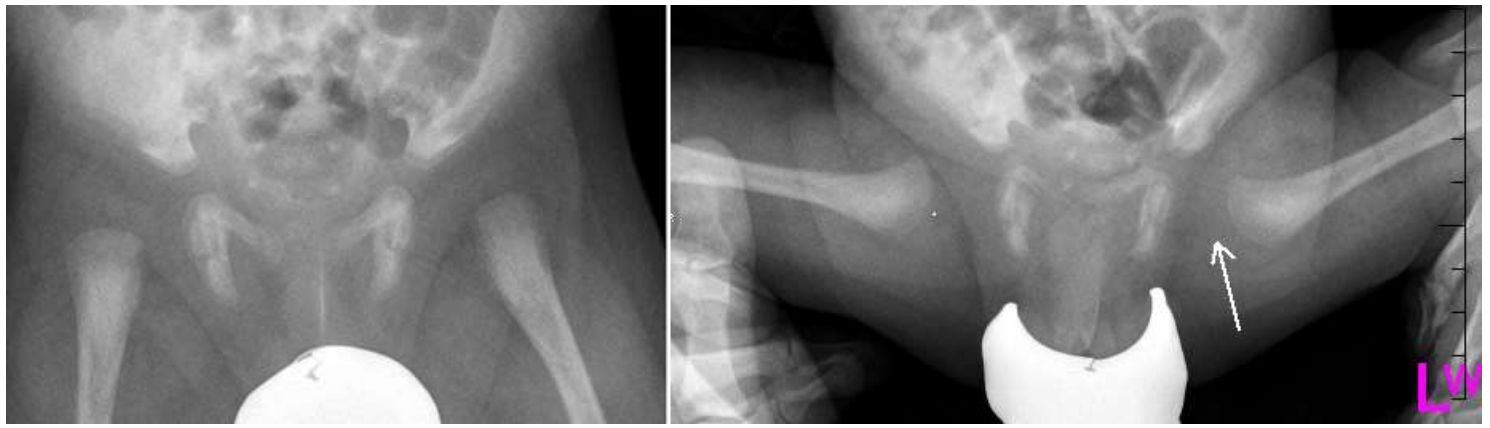

Figure 2. Radiographs: Antero-posterior (AP) and Lauensteun view of three weeks old child's left hip, slightly out of the socket (eccentric hip).

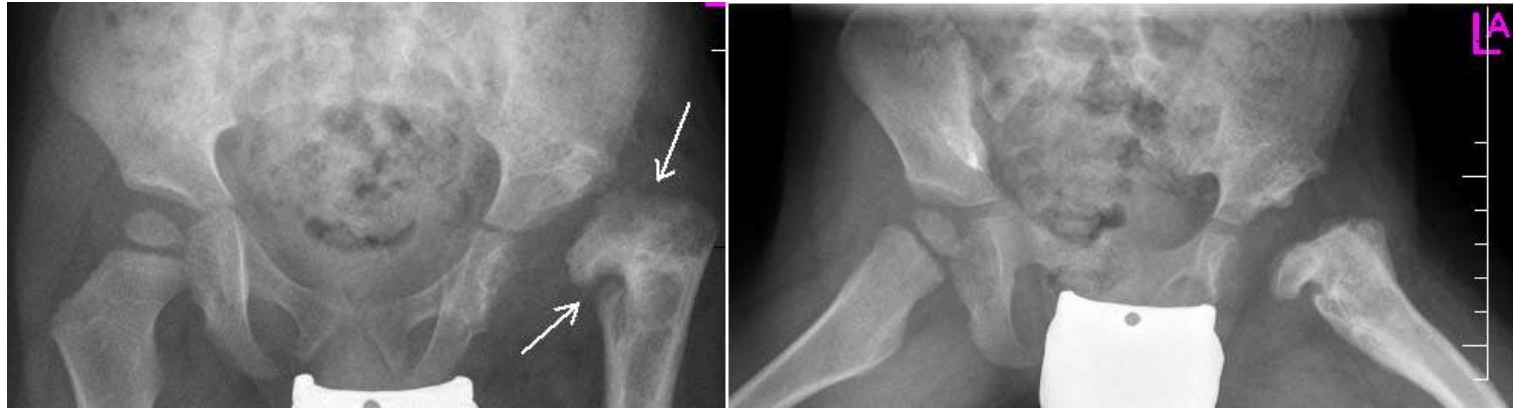

Figure 3. Radiographs: AP and Lauensteun with postrezidual deformity in the same patient after 2 years.

\section{Study Designs}

\subsection{Genome Wide Association Studies}

Genome Wide Association Studies (GWAS) are systematic observational studies, which analyze genome-wide set of genetic variants preferably in a large number of different individuals to determine if any of the observed variants are associated with a trait. Genome Wide Association Studies usually focuses on the correlation between single nucleotide polymorphisms (SNPs) to identify variants in the susceptible genes associated with certain diseases [1]. 
Several musculoskeletal disorders were discovered through GWAS. Sun et al. [16] conducted a large GWAS to study DDH and found 12 variants in the ubiquinol-cytochrome $\mathrm{C}$ reductase complex chaperone $(U Q C C)$ gene to be associated with $\mathrm{DDH}$. Ubiquinol-cytochrome $\mathrm{C}$ reductase complex chaperone plays a role in spine and bone formation.

Many genes of interest have been found to be associated with DDH such as COL1A1, GDF5, HOXB9, ASPN, VDR, IL6-gene, and HOXD9 [6,10,17-22]. Those genes are found to help the bone formation and chondrogenesis in large case-control studies among the Chinese and Caucasian populations (Table 1).

Table 1. List of the gene variants associated with DDH.

\begin{tabular}{|c|c|c|c|c|c|}
\hline $\begin{array}{l}\text { Genomic } \\
\text { Design }\end{array}$ & $\begin{array}{l}\text { Polymorphism/ } \\
\text { Mutations }\end{array}$ & $\begin{array}{c}\text { Chromosomal } \\
\text { Location }\end{array}$ & Genes & Location & References \\
\hline GWAS & rs6060373 & $20 q 11.22$ & UQCC & China & [16] \\
\hline CGAA & rs143383 & $20 q 11.22$ & $\widetilde{G D F-5}$ & China & [23] \\
\hline CGAA & $\begin{array}{l}\text { Aspartic acid }(\mathrm{D}) \\
\text { repeats }\end{array}$ & $9 q 22.31$ & $A S P N$ & China & [2] \\
\hline CGAA & rs711819 & $2 q 31.1$ & HOXD9 & China & [22] \\
\hline CGAA & rs3744448 & $17 q 23.2$ & TBX4 & China & [17] \\
\hline CGAA & rs276252 & $20 q 11.22$ & РАРPA2 & China & \\
\hline CGAA & rs113647555 & $17 q 21.33$ & COL1A1 & China & [21] \\
\hline CGAA & rs1800796 & 7p15.3 & $I L-6$ & Croatia & [20] \\
\hline CGAA & rs1800470 & $19 \mathrm{q} 13.2$ & TGF B1 & Croatia & [20] \\
\hline CGAA & rs3732378 & $3 q 22.2$ & CX3CR1 & America & [24] \\
\hline GWLA & Unknown & $17 q 21.31-17 q 22$ & $17 q 21.31-17 q 22$ & China, America & [25] \\
\hline GWLA & Unknown & $13 q 22$ & $13 q 22$ & Japan & [26] \\
\hline
\end{tabular}

GWAS: Geniomic Wide Association Studies; CGAA: Candidate Gene Association Analyses; GWLA: Genome Wide Linkage Analyses.

Genome Wide Association Studies are used to find genome wide or candidate associations, out of which the Candidate Gene Association Analyses (CGAA) are more important and widely studied in the context of developmental dysplasia of the hip.

\subsection{Genome Wide Linkage Analysis}

Genome Wide Linkage Analyses (GWLA) are systematic studies, that utilize pedigrees to identify loci associated with a disease and are also used in genetic mapping of traits with genetic predisposition. Genome Wide Linkage Analyses are based on the tendency, that two loci are inherited together. These studies demonstrate several chromosome region segregations with trait phenotype in large family pedigree [25].

Reviewing the literature showed that large pedigree of families with $\mathrm{DDH}$ had a $4 \mathrm{Mb}$ region on chromosome 17q21.32 [25]. Moreover, the analysis of large multigenerational families of DDH showed a linkage to chromosomes 4q35, 13q22, and 16p [23,27]. A GWAS study from a large four generation Japanese family with history of acetabular dysplasia found a linkage of DDH with specific regions at chromosome 13 [26].

\subsection{Global Copy Number Variants Detection}

DNA sequence diversity within the human genome is said to be more affected by Global Copy Number Variants (CNVs) than SNPs. The importance of CNVs in genome wide association studies is becoming widely accepted, but the optimal method to identify these variants is still in question. Older methods e.g., fluorescence in situ hybridization (FISH) lacked in genetic resolution and could identify only large repeats. Recently, high throughput genomic sequencing method has great potential to enhance $\mathrm{CNV}$ diagnostic. Copy number variants are submicroscopic genomic alterations that might affect a considerable number of DNA base pairs either by duplication or deletion [28]. Copy Number Variants are involved in the disease by changing the copy numbers of dosage sensitive genes or disrupting the gene coding regions [1,29]. Moreover, non-allelic homologous recombination and 
end-joining were reported in the genomic rearrangement and formation of CNVs [29]. CNVs have been studied in Mendelian diseases and neurological diseases such as Schizophrenia and autism [29,30]. However, it is not implicated yet in DDH. Therefore, such a step would lead to very promising findings to better understanding the molecular and genetic basis of DDH [31].

\subsection{Whole Exome Sequencing}

Whole Exome Sequencing (WES) is a genomic method for sequencing used to sequence all protein coding portions (exome) of the genome and to identify variants in all individual genes [1]. This method can be applied to both clinical and research diagnostic, because these variants are responsible for polygenic and also Mendelian diseases. WES has been used to identify several hereditary and musculoskeletal abnormalities [24,32]. Such techniques had a novel impact on identification of variant involvement in DDH, e.g., Feldman et al. [31] used WES in large pedigree segregating DDH and identified those variants in chemokine receptor genes (CX3CR1) was implicated in the pathology of DDH. Both linkage analysis studies and exome data supported the association of CX3CR1 and DDH (Table 1). Zhu et al. [33] found, that the ribosome biogenesis factor (BMS1) is associated with DDH, because it affects mineral density and resorption in bones.

\section{Discussion}

Despite the lack of universal formal agreement about DDH screening, early diagnosis and management of DDH were proved to prevent long-term disabilities and provide the best clinical outcomes $[9,33]$.

\subsection{Description of Screening System}

Neonatal hip examination (Ortolani and Barlow maneuvers) is the initial and most important part of DDH screening program [9,33,34]. Ultrasonography is considered the most reliable for screening in children less than 3 years, however, pelvic imaging is the standard method after the age of 3 years [34]. Yet, such tools might fail to detect subtle DDH [11,13].

\subsection{Previous Reports of Screening Results}

Sahin et al. [35] conducted a study to screen DDH in 5798 patients for 7 years and they concluded that serial physical examination has a very good positive predictive value in high-risk families. Gardner et al. [36] found that the use of hip U/S decreases the rates of complications and improves the quality of life and psychological health in the children.

Two randomized controlled trials from Norway demonstrated that ultrasonographic screening helped to decrease the prevalence of late DDH presentation from 2.6-3 cases/1000 live birth to $0.7-1$ cases/1000 live birth [37,38].

\subsection{Previous Reports of the Risk Factors of Development Dysplasia of the Hip}

The cause of DDH is multifactorial [3,10]. The genetic implication of DDH is now well-understood. Historically, Carter et al. [39] suggested the presence of two genetic theories for DDH; first is the polygenic inheritance to acetabular dysplasia; the second related to the autosomal dominance with incomplete penetrance. Moreover, DDH is characterized by a variable expression in the phenotype depending on the degree of femoral head uncoverage [1].

Kremli et al. [3] illustrated the importance of positioning and ethnic differences in the prevalence of DDH by reporting the very low prevalence of DDH in communities that carry children around the waist of mothers with the hips abducted and flexed such as India, China, and Africa. On the other hand, some studies reported that breech presentation is the single most important risk factor to develop DDH in $2-27 \%$ of children [40]. 


\subsection{Descriptions of Development Dysplasia of the Hip Complications}

Development dysplasia of the hip if left untreated, will lead to premature OA and long-term handicaps [1,5]. Avascular necrosis of the hip affects $60 \%$ of DDH patients due to surgical and nonsurgical intervention [41]. Williams et al. [42] reported that that risk of femoral head avascular necrosis is less than $1 \%$ with early detection and treatment with Pavlik harness.

Studies of large families and genome-wide association studies helped to localize the genes and SNPs associated with DDH and OA. Functional SNP in FGF-2 and GDF5 were reported to be associated with OA secondary to DDH $[16,23]$.

\section{Conclusions}

In 2016 Shaw et al. [43] published the new guidelines for evaluation and referral for DDH in infants, but authors still have trouble reaching consensus on diagnostic imaging in adults. The importance of more thorough research of genes associated with DDH and their variations is crucial to understanding this disorder and can lead to entirely different approach in screening of DDH.

Genetic examination, early screening and treatment can lead to much higher effectivity in treatment and decreasing the risk of developing early OA or movement impairment, which means that, early prevention of DDH and its complications emphasizes the awareness to establish a universal screening program for newborns, that would be used internationally. Such a system, along with genetic counseling, will add value in the management of DDH as early as possible and, thus, lead to better and earlier individualized treatment. We consider screening newborns to be the most effective way to maximize the benefit for these patients. Family members of patients can benefit from such a screening program due to familiar occurrence of $\mathrm{DDH}$, although such a widespread screening program will be difficult to implement at first. Problems might arise in the availability of specialized personnel and it can also prove to be an economical strain.

Author Contributions: R.Z. and M.K. coordinated the writing and edited the final text. S.H., D.A. and L.D. contributed to the bibliographical revision, early editing and drew up the text.

Funding: This research was funded by The Ministry of Education, Science, Research and Sport of the Slovak Republic, grant number VEGA 1/0255/17.

Conflicts of Interest: The authors declare no conflict of interest.

\section{References}

1. Basit, S.; Hannan, M.A.; Khoshhal, K.I. Developmental dysplasia of the hip: Usefulness of next generation genomic tools for characterizing the underlying genes-A mini review. Clin. Genet. 2016, 90, 16-20. [CrossRef] [PubMed]

2. Shi, D.; Dai, J.; Zhu, P.; Qin, J.; Zhu, L.; Zhu, H.; Zhao, B.; Qiu, X.; Xu, Z.; Chen, D.; et al. Association of the D repeat polymorphism in the ASPN gene with developmental dysplasia of the hip: A case-control study in Han Chinese. Res. Ther. 2011, 13, R27. [CrossRef] [PubMed]

3. Kremli, M.K.; Alshahid, A.H.; Khoshhal, K.I.; Zamzam, M.M. The pattern of developmental dysplasia of the hip. Saudi Med. J. 2003, 24, 1118-1120. [PubMed]

4. Emans, J.B.; Mooney, J.F. Developmental Dislocation of the Hip: A Clinical Overview. Pediatr. Rev. 1995, 16, 299-303.

5. Kotlarsky, P.; Haber, R.; Bialik, V.; Eidelman, M. Developmental dysplasia of the hip: What has changed in the last 20 years? J. Orthop. 2015, 6, 886-901. [CrossRef]

6. Kolundžić, R.; Trkulja, V.; Mikolaučić, M.; Kolundžić, M.J.; Pavelić, S.K.; Pavelić, K. Association of interleukin-6 and transforming growth factor- $\beta 1$ gene polymorphisms with developmental hip dysplasia and severe adult hip osteoarthritis: A preliminary study. Cytokine 2011, 54, 125-128. [CrossRef] [PubMed]

7. Feldman, G.J.; Peters, C.L.; Erickson, J.A.; Hozack, B.A.; Jaraha, R.; Parvizi, J. Variable expression and incomplete penetrance of developmental dysplasia of the hip: Clinical challenge in a 71-member multigeneration family. J. Arthroplasty 2012, 27, 527-532. [CrossRef] [PubMed] 
8. Wilkinson, J.A. Etiologic Factors in Congenital Displacement of the Hip and Myelodysplasia. Clin. Orthop. Relat. Res. 1992, 75. [CrossRef]

9. Ortolani, M. Un Segno poco noto e sua importanza per la diagnosi precoce di prelussazione congenita dell'anca. Paediatria Napoli. 1937, 45, 129-136.

10. Rubini, M.; Cavallaro, A.; Calzolari, E.; Bighetti, G.; Sollazzo, V. Exclusion of COL2A1 and VDR as Developmental Dysplasia of the Hip Genes. Clin. Orthop. Relat. Res. 2008, 466, 878-883. [CrossRef]

11. Volovik, I.; Rishpon, S.; Sabi, R.; Stein-Zamir, C.; Stein-Zamir, C. Developmental dysplasia of the hip: Risk markers, clinical screening and outcome. Pediatr. Int. 2008, 50, 341-345.

12. Bialik, V.; Bialik, G.M.; Blazer, S.; Sujov, P.; Wiener, F.; Berant, M. Developmental Dysplasia of the Hip: A New Approach to Incidence. Pediatrics 1999, 103, 93-99. [CrossRef] [PubMed]

13. Rhodes, A.M.L.; Clarke, N.M.P. A review of environmental factors implicated in human developmental dysplasia of the hip. J. Child. Orthop. 2014, 8, 375-379. [CrossRef] [PubMed]

14. Jawadi, A.H.; Wakeel, A.; Tamimi, W.; Nasr, A.; Iqbal, Z.; Mashhour, A.; Fattah, M.A.; Alkhanein, N.; Abu Jaffal, A.S. Association analysis between four vitamin D receptor gene polymorphisms and developmental dysplasia of the hip. J. Genet. 2018, 97, 925-930. [CrossRef]

15. Al-Essa, R.S.; Aljahdali, F.H.; Alkhilaiwi, R.M.; Philip, W.; Jawadi, A.H.; Khoshhal, K.I. Diagnosis and treatment of developmental dysplasia of the hip: A current practice of paediatric orthopaedic surgeons. J. Orthop. Surg. 2017, 25, 1-7. [CrossRef] [PubMed]

16. Sun, Y.; Wang, C.; Hao, Z.; Dai, J.; Chen, D.; Xu, Z.; Shi, D.; Mao, P.; Teng, H.; Gao, X.; et al. A Common Variant of Ubiquinol-Cytochrome C Reductase Complex Is Associated with DDH. PLoS ONE 2015, 10, e0120212. [CrossRef] [PubMed]

17. Shi, D.; Wang, K.; Jiang, Q. Association of a single nucleotide polymorphism in Tbx4 with developmental dysplasia of the hip: A case-control study. Osteoarthr. Cartil. 2010, 18, S208. [CrossRef]

18. Liu, S.; Tian, W.; Wang, J.; Cheng, L.; Jia, J.; Ma, X. Two Single-Nucleotide Polymorphisms in the DKK1 Gene Are Associated with Developmental Dysplasia of the Hip in the Chinese Han Female Population. Genet. Test. Mol. Biomarkers 2014, 18, 557-561. [CrossRef] [PubMed]

19. Basit, S.; Alharby, E.; Albalawi, A.M.; Khoshhal, K.I. Whole genome SNP genotyping in a family segregating developmental dysplasia of the hip detected runs of homozygosity on chromosomes 15q13.3 and 19p13.2. Congenit. Anom. 2018, 58, 56-61. [CrossRef]

20. Čengić, T.; Trkulja, V.; Pavelić, S.K.; Ratkaj, I.; Markova-Car, E.; Mikolaučić, M.; Kolundžić, R. Association of TGFB1 29C/T and IL6 -572G/C polymorphisms with developmental hip dysplasia: A case-control study in adults with severe osteoarthritis. Int. Orthop. 2015, 39, 793-798. [CrossRef]

21. Zhao, L.; Tian, W.; Pan, H.; Zhu, X.; Wang, J.; Cheng, Z.; Cheng, L.; Ma, X.; Wang, B. Variations of the COL1A1 Gene Promoter and the Relation to Developmental Dysplasia of the Hip. Genet. Test. Mol. Biomarkers 2013, 17, 840-843. [CrossRef] [PubMed]

22. Tian, W.; Zhao, L.; Wang, J.; Suo, P.; Wang, J.; Cheng, L.; Cheng, Z.; Jia, J.; Kan, S.; Wang, B.; et al. Association analysis between HOXD9 genes and the development of developmental dysplasia of the hip in Chinese female Han population. BMC Musculoskelet. Disord. 2012, 13, 59. [CrossRef] [PubMed]

23. Dai, J.; Shi, D.; Zhu, P.; Qin, J.; Ni, H.; Xu, Y.; Yao, C.; Zhu, L.; Zhu, H.; Zhao, B.; et al. Association of a single nucleotide polymorphism in growth differentiate factor 5 with congenital dysplasia of the hip: A case-control study. Res. Ther. 2008, 10, R126. [CrossRef] [PubMed]

24. Feldman, G.J.; Parvizi, J.; Levenstien, M.; Scott, K.; Erickson, J.A.; Fortina, P.; Devoto, M.; Peters, C.L. Developmental Dysplasia of the Hip: Linkage Mapping and Whole Exome Sequencing Identify a Shared Variant in CX3CR1 in All Affected Members of a Large Multigeneration Family. J. Bone Miner. Res. 2013, 28, 2540-2549. [CrossRef]

25. Feldman, G.; Dalsey, C.; Fertala, K.; Azimi, D.; Fortina, P.; Devoto, M.; Pacifici, M.; Parvizi, J. The Otto Aufranc Award: Identification of a $4 \mathrm{Mb}$ region on chromosome 17q21 linked to developmental dysplasia of the hip in one 18-member, multigeneration family. Clin. Orthop. Relat. Res. 2010, 468, 337-344. [CrossRef] [PubMed]

26. Mabuchi, A.; Nakamura, S.; Takatori, Y.; Ikegawa, S. Familial Osteoarthritis of the Hip Joint Associated with Acetabular Dysplasia Maps to Chromosome 13q. Am. J. of Hum. Genet. 2006, 79, 163-168. [CrossRef] [PubMed] 
27. Loughlin, J.; Mustafa, Z.; Irven, C.; Smith, A.; Carr, A.J.; Sykes, B.; Chapman, K. Stratification Analysis of an Osteoarthritis Genome Screen-Suggestive Linkage to Chromosomes 4, 6, and 16. Am. J. Hum. Genet. 1999, 65, 1795-1798. [CrossRef] [PubMed]

28. Grayton, H.M.; Fernandes, C.; Rujescu, D.; Collier, D.A. Copy number variations in neurodevelopmental disorders. Prog. Neurobiol. 2012, 99, 81-91. [CrossRef]

29. Chaudhry, A.; Noor, A.; Degagne, B.; Baker, K.; Bok, L.A.; Brady, A.F.; Chitayat, D.; Chung, B.H.; Cytrynbaum, C.; Dyment, D.; et al. Phenotypic spectrum associated with PTCHD1 deletions and truncating mutations includes intellectual disability and autism spectrum disorder. Clin. Genet. 2015, 88, 224-233. [CrossRef] [PubMed]

30. Boone, P.M.; Yuan, B.; Campbell, I.M.; Scull, J.C.; Withers, M.A.; Baggett, B.C.; Beck, C.R.; Shaw, C.J.; Stankiewicz, P.; Moretti, P.; et al. The Alu-Rich Genomic Architecture of SPAST Predisposes to Diverse and Functionally Distinct Disease-Associated CNV Alleles. Am. J. Hum. Genet. 2014, 95, 143-161. [CrossRef]

31. Rouault, K.; Scotet, V.; Autret, S.; Gaucher, F.; Dubrana, F.; Tanguy, D.; El Rassi, C.Y.; Fenoll, B.; Férec, C. Evidence of association between GDF5 polymorphisms and congenital dislocation of the hip in a Caucasian population. Osteoarthr. Cartil. 2010, 18, 1144-1149. [CrossRef] [PubMed]

32. Basit, S.; Alharby, E.; AlBalawi, A.M.; Khoshhal, K.I. Exome sequencing identified rare variants in genes HSPG2 and ATP2B4 in a family segregating developmental dysplasia of the hip. BMC Med. Genet. 2017, 18, 34. [CrossRef] [PubMed]

33. Zhu, L.-Q.; Su, G.-H.; Dai, J.; Zhang, W.-Y.; Yin, C.-H.; Zhang, F.-Y.; Zhu, Z.-H.; Guo, Z.-X.; Fang, J.-F.; Zou, C.-D.; et al. Whole genome sequencing of pairwise human subjects reveals DNA mutations specific to developmental dysplasia of the hip. Genomics 2018, in press. [CrossRef] [PubMed]

34. American Institute of Ultrasound in Medicine. American College of Radiology AIUM practice guideline for the performance of an ultrasound examination for detection and assessment of developmental dysplasia of the hip. J. Ultrasound Med. 2009, 28, 114-119. [CrossRef]

35. Sahin, F.; Aktürk, A.; Beyazova, U.; Cakir, B.; Boyunaga, O.; Tezcan, S.; Bolukbasi, S.; Kanatli, U. Screening for developmental dysplasia of the hip: Results of a 7-year follow-up study. Pediatr. Int. 2004, 46, 162-166. [CrossRef] [PubMed]

36. Gardner, F.; Dezateux, C.; Elbourne, D.; Gray, A.; King, A.; Quinn, A.; Collaborative Hip Trial Group. The hip trial: Psychosocial consequences for mothers of using ultrasound to manage infants with developmental hip dysplasia. Arch. Dis. Child. Fetal Neonatal Ed. 2005, 90, 17-24. [CrossRef] [PubMed]

37. Holen, K.J.; Tegnander, A.; Bredland, T.; Johansen, O.J.; Saether, O.D.; Eik-Nes, S.H.; Terjesen, T. Universal or selective screening of the neonatal hip using ultrasound? A prospective, randomised trial of 15,529 newborn infants. J. Bone Joint Surg. Br. 2002, 84, 886-890. [CrossRef] [PubMed]

38. Roposch, A.; Liu, L.Q.; Protopapa, E. Variations in the Use of Diagnostic Criteria for Developmental Dysplasia of the Hip. Clin. Orthop. Relat. Res. 2013, 471, 1946-1954. [CrossRef]

39. Carter, C.; Wilkinson, J. Persistent joint laxity and congenital dislocation of the hip. J. Bone Jt. Surg. 1964, 46, 40-45. [CrossRef]

40. Warman, M.L.; Cormier-Daire, V.; Hall, C.; Krakow, D.; Lachman, R.; LeMerrer, M.; Mortier, G.; Mundlos, S.; Nishimura, G.; Rimoin, D.L.; et al. Nosology and Classification of Genetic Skeletal Disorders: 2010 Revision. Am. J. Med. Genet. A 2011, 155, 943-968. [CrossRef]

41. Suzuki, S.; Yamamuro, T. Avascular necrosis in patients treated with the Pavlik harness for congenital dislocation of the hip. J. Bone Jt. Surg. 1990, 72, 1048-1055. [CrossRef]

42. Williams, P.R.; Jones, D.A.; Bishay, M. Avascular necrosis and the Aberdeen splint in developmental dysplasia of the hip. J. Bone Jt. Surgery. Br. Vol. 1999, 81, 1023-1028. [CrossRef]

43. Segal, L.S.; Shaw, B.A. Evaluation and Referral for Developmental Dysplasia of the Hip in Infants. Pediatrics 2016, 138, e20163107.

(C) 2019 by the authors. Licensee MDPI, Basel, Switzerland. This article is an open access article distributed under the terms and conditions of the Creative Commons Attribution (CC BY) license (http://creativecommons.org/licenses/by/4.0/). 